\title{
Optimization of Ultrasonic-assisted Extraction of Total Phenolic Compound from Leaves of Chromolaena Odorata L. Using Response Surface Methodology
}

\author{
Guntima SIRIJEERACHAI $^{1 *}$, Suphattra KHUNASINKUN ${ }^{1}$, Piyapassara BOONLEAU ${ }^{1}$, Ratchadaporn OONSIVILAI ${ }^{2}$, and \\ Aroonsri NUCHITPRASITCHAI ${ }^{1}$ \\ ${ }^{1}$ School of Chemical Engineering, Institute of Engineering, Suranaree University of Technology, Muang Nakhon Ratchasima 30000 \\ Thailand \\ ${ }^{2}$ School of Food Technology, Institute of Agricultural Technology of Technology, Muang Nakhon Ratchasima 30000, Thailand
}

\begin{abstract}
Chromolaena odorata L. or C. odorata is a weed that found in tropical continents . Leaves, roots and flowers of $\mathrm{C}$. odorata have been used as medicinal plants for centuries. Preliminary phytochemical screening showed the chemical composition of its extracts having phenolic compounds such as flavonoids, saponins, tannins and steroids. The total phenolic compounds (TPC) in medicinal plants are acknowledged as biochemical activities such as antiinflammatory, antiviral, antimicrobial, antioxidant agents and etc. This work is interested in antioxidant and antimicrobial activity of an ethanolic extract of $C$. odorata leaves. Though, many solvents can be used to extract TPC from plants. Ethanol with ultrasound assisted extraction was selected. The response surface methodology coupled with the nonlinear solver were used to find the optimal extraction variables. The Central Composite Design (CCD) was employed as the sampling technique. Three variables are the ratio of ethanol to the dried leaves of $C$. odorata $\left(X_{1}\right)$, aqueous ethanol concentration $\left(\mathrm{X}_{2}\right)$, and the extraction time $\left(\mathrm{X}_{3}\right)$. The extraction conditions were fixed at $40 \mathrm{kHz}$ and $60{ }^{\circ} \mathrm{C}$. The maximum yield of TPC was $111.77 \mathrm{mg} \mathrm{GAE} / \mathrm{g}$ dry extract at $57 \%$ $\mathrm{v} / \mathrm{v}$ of aqueous ethanol concentration, $43 \mathrm{~mL}$ of solvent $/ \mathrm{g}$ of dried sample and 35 minutes extraction time.
\end{abstract}

\section{Introduction}

Chromolaena odorata L. or C. odorata with several common names i.e. Siam weed, Bitter bush, Christmas bush, Devil weed, and Camphor grass, is a weed in the sunflower family, Asteraceae, that found in tropical continents. It is a fast-growing perennial and invasive weed. It is native to South and Central America and has been spread out into Asia, Africa and Australia (Akinmoladun et al., 2007). Siam weed's economic value is low as it allelopathic potentialities and growth inhibitors and suppress young plantations and other ecosystem (Akinmoladun et al., 2007). However, its tremendous medicinal properties have been found from all parts of this Siam weed. Leaves, roots and flowers of C. odorata have been used as medicinal plants for centuries .In Thailand, young leaves are crushed by hands and the resulting liquid can be used to treat skin wounds and blood coagulation. Preliminary phytochemical screening showed the chemical composition of C. odorata extracts having phenolic compounds such as flavonoids, saponins, tannins and steroids. The total phenolic compounds (TPC) in medicinal plants are largely acknowledged as biochemical activities such as antiinflammatory, antiviral, antimicrobial, anti-mutagenic, anti carcinogenic and especially antioxidant agents. This work is interested in antioxidant and antimicrobial activity of an ethanolic extract of C. odorata leaves.

\subsection{Total phenolic compounds}

Phenolic compounds found in medicinal plants have an aromatic ring bearing one or more hydroxyl groups as shown in Figure 1. There are about 8000 naturally plant phenolics and $50 \%$ of them are flavonoids (Sulaiman and Balachandran, 2012). Phenolics possess a lot of biochemical activities such as antioxidant, antimutagenic, anticarcinogenic and are the largest group of phytochemicals that account for most of the antioxidant activity in plants or plant products (Okpuzar et al., 2009). Flavonoids have two benzene rings separated by a propane unit as shown in Figure 1. Flavones and flavonols are the most widely distributed of all the phenolics (Sulaiman and Balachandran, 2012). Flavonoids are predominantly beneficial. They are acting as antioxidants and giving protection against cardiovascular disease, definite forms of cancer and age-related degeneration of cell components. Moreover, flavonoids possess pharmacological effects to inhibit the release of

\footnotetext{
* Corresponding author: guntima@g.sut.ac.th
} 
histamines, the adhesion of blood platelets and the action of lens aldose reductase, to block the inflammatory effects, and to act as a heart-stimulant (Sulaiman and Balachandran, 2012). As the very important of flavonoids, this work firstly interested in finding an optimization of flavonoids extraction condition of Siam weed using UAE. Nevertheless, due to the limitation of the experiment, the optimization of total phenolic compounds from Siam weed extraction is focused.

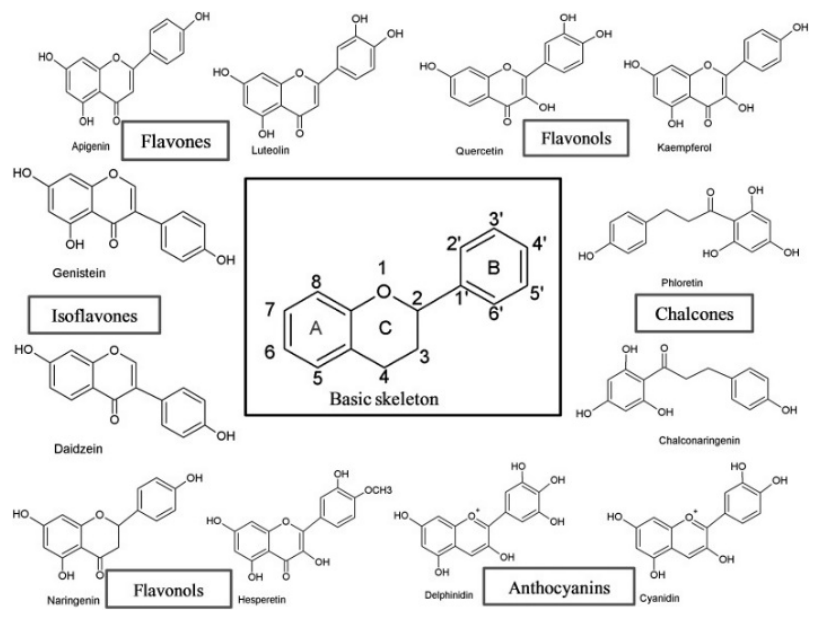

Figure 1. Basic structures of flavonoids (Panche et al., 2016)

\subsection{Literature review}

From the excellent and diverse nutritional and pharmaceutical industry values, C. odorata leaf extract brings the attention of researchers. The quality of $\mathrm{C}$. odorata extracts and their pharmacological activities depend on the starting biomass (climatic conditions, geographical location, harvest and storage conditions) and the selection of an adequate extraction method (Alara et al., 2019)

Extraction is the main step to separate the bioactive phytochemicals such as TPC and flavonoids from plant materials. The extraction method of TPC from plants can be done by several techniques and solvents. Liquid-liquid and solid-liquid extraction are the most commonly used procedures because of their ease of use, efficiency, and wide-ranging applicability. Commonly used extraction solvents are alcohols (methanol, ethanol), acetone, diethyl ether, and ethyl acetate. Other factors, such as $\mathrm{pH}$, temperature, sample to-solvent volume ratio, and the number and time intervals of individual extraction steps, also play an important role in the extraction procedure (Stalikas, 2007)

Clean flavonoid extracts and free from compounddegradation can be performed using supercritical fluid extraction (SFE). In addition the extract is free from chlorophyll and other nonpolar compounds as they are insoluble in supercritical $\mathrm{CO}_{2}$. Because of polarity of flavonoids, adding organic modifiers such as methanol is used to to increase the solvating power of supercritical $\mathrm{CO}_{2}$ (Stalikas, 2007).
Microwave-assisted extraction (MAE) is one of the methods employed in extracting TPC from plant samples. It is widely used because of its cost-effectiveness, yielding excessive TPC in lesser extraction time with the use of a minimal solvent relative to conventional techniques. However, high microwave power and temperature might degrade the TPC and reduce the yield of TPC (Alara et al., 2019).

Ultrasound-assisted extraction (UAE) is one of the main applications in food industry. The optimal UAE conditions were obtained using response surface methodology (RSM) with extraction temperature of $56^{\circ} \mathrm{C}$, extraction time of $3 \mathrm{~min}$, duty cycle of $0.6 \mathrm{~s}$, and solid to solvent ratio of $3.6 \%$. At the optimum conditions, the TPC content and antioxidant activity (AA) were measured 4.04 $\mathrm{mg} / \mathrm{g}$ and $68.9 \%$, respectively. It was found that the linear term of temperature had the most effect on TPC content and AA. This research exposed that UAE is an effective method to extract phenolic compounds from olive cake.

Recently, extraction of TPC was performed by using UAE. The optimization of TPC extraction from rhizomes of Rheummoorcroftianum using response surface methodology (RSM). A four-factors-three-level and BoxBehnken Design (BBD) was used to fit the model. This study found that the polyphenolic content and antioxidant activity was significantly $(\mathrm{p}<0.05)$ affected by vessel diameter $-6 \mathrm{~cm} \quad\left(\mathrm{X}_{1}\right)$, sample to solvent ratio$1: 28.42 \mathrm{~g} / \mathrm{mL}\left(\mathrm{X}_{2}\right)$ and extraction temperature $-37.11^{\circ} \mathrm{C}$ $\left(\mathrm{X}_{3}\right)$. The measured parameters were found in accordance with the predicted values (Pandey et al., 2018).

UAE extraction for flavonoids-enriched extract from Folium eucommiae using the central composite design (CCD) combined with RSM was used to optimise extraction conditions. It was found that the highest extraction ratio of flavonoids is $17.2 \%$ using $40 \%$ ethanol as solvent and 1:60 solid to lipid ratio for $70 \mathrm{~min}$ extraction (Huang et al., 2009).

UAE of total flavonoids from leaves of Syringa Oblata Lindl. was studied. The extraction conditions were: $1 \mathrm{~g}$ plant sample with $20 \mathrm{~mL}$ of $50 \%$ ethanol, at $60^{\circ} \mathrm{C}$ for 50 min, which a yield of total flavonoids of $92.00 \pm 0.87 \mathrm{mg} / \mathrm{g}$ of plant (Sheng et al., 2014).

UAE of flavonoids from Camellia fascicularis leaves was optimized using RSM. It was found that the optimal extracting conditions are the ratio of liquid to raw material of $60 \mathrm{~mL} / \mathrm{g}$, ethanol concentration of $40 \%$, extraction temperature of $72.3^{\circ} \mathrm{C}$, and extraction time of $1.6 \mathrm{~h}$, which contributed to the highest flavonoids yield of $4.765 \%$ (Liu et al., 2017).

It was found that the traditional extraction methods are very time-consuming and need large amount of solvents for bioactive compounds (Azmir et al., 2013). Some solvents such as methanol and diethyl ether are considered hazardous. Currently, several modern extraction methods such as enzymatic extraction, UAE, and SFE have been developed for extraction of phenolic compounds or flavonoids. The UAE is less expensive and much easier compared to MAE and SFE. This work therefore using UAE as the method to extract TPC from Siam weed.

\section{Methodology}




\subsection{Material}

C. odorata or Siam weed was collected in June, 2018 from Plant Genetic Conservation Project Under the Royal Initiation of Her Royal Highness Princess Maha Chakri Sirindhorn (RSPG), Sikhiu District, Nakhon Ratchasima Province, Thailand. The weed was washed and dried at 60 ${ }^{\circ} \mathrm{C}$ for 24 hours. The dried weed was grinding and sieving. The water content was determined and the samples were kept in $4^{\circ} \mathrm{C}$.

\subsection{Extraction and analysis method}

Dried C. odorata was extracted by using UAE upon the selected conditions. The extracts were filtered and evaporated to remove ethanol using rotary evaporator. The extracts were then freeze dried to remove water. After that the dried extract were analysed the amount of TPC using Folin-Ciocalteu standard method.

\subsection{Experimental design}

This study aimed to use non hazardous solvent. Ethanol and water were selected as a mixed solvent. Dependent variable is yield of TPC. The independent variables are ratio of solvent to material, ethanol concentration, extraction temperature, extraction time and frequency of the ultrasound. Because of the important of flavonoids values. The optimum conditions of flavonoid extraction from 3 papers as cited in the literature were used and compared as the central criteria as shown in Table 1.

Table 1. The UAE of flavonoid Optimal conditions from literatures

\begin{tabular}{lccc}
\hline \multicolumn{1}{c}{$\begin{array}{c}\text { Independent } \\
\text { Variables }\end{array}$} & $\begin{array}{c}\text { Sheng } \text { et } \\
\text { al, (2014) }\end{array}$ & $\begin{array}{c}\text { Liu } \text { et al. } \\
(2017)\end{array}$ & $\begin{array}{c}\text { Huang } \text { et } \\
\text { al. }(2009)\end{array}$ \\
\hline $\begin{array}{l}\text { Ratio of solvent to } \\
\text { sample }(\mathrm{mL} / \mathrm{g})\end{array}$ & 20 & 60 & 60 \\
\hline $\begin{array}{l}\text { Ethanol } \\
\text { concentration } \\
(\% \text { by wt) }\end{array}$ & 50 & 40 & 40 \\
\hline $\begin{array}{l}\text { Extraction } \\
\text { temperature }\left({ }^{\circ} \mathrm{C}\right)\end{array}$ & 60 & 72.3 & 55 \\
\hline $\begin{array}{l}\text { Extraction time } \\
\text { (min) }\end{array}$ & 50 & 96 & 70 \\
\hline $\begin{array}{l}\text { Frequency } \\
\text { Yield of } \\
\text { flavonoids }(\mathrm{mg} / \mathrm{g})\end{array}$ & $93.07 \pm 0.71$ & 47.7 & 172 \\
\hline
\end{tabular}

From Table 1, it was found that the important variables were ratio of solvent to sample $\left(\mathrm{X}_{1}\right)$, ethanol concentration $\left(\mathrm{X}_{2}\right)$, and extraction time $\left(\mathrm{X}_{3}\right)$. The UAE conditions were fixed at $40 \mathrm{kHz}$ and $60{ }^{\circ} \mathrm{C}$. The Central Composite Design or CCD was used for experimental design.

The central values of $X_{1}, X_{2}$ and $X_{3}$ were chosen as 60 $\mathrm{mL} / \mathrm{g}, 40 \%(\mathrm{v} / \mathrm{v})$ and $70 \mathrm{~min}$. respectively. The factor interval for $X_{1}$ and $X_{2}$ were chosen at 10 , and 20 for $X_{3}$. The design experiment is shown in Table 2. Table 3 shows the designed variables used in the 20 experimental conditions.

Table 2. The experimental design for UAE Flavonoid

\begin{tabular}{lccccc}
\hline \multicolumn{1}{c}{$\begin{array}{c}\text { Independent } \\
\text { Variables }\end{array}$} & \multicolumn{5}{c}{ Factor Level } \\
\hline $\begin{array}{l}\text { Ratio of solvent to } \\
\text { sample } \\
\left(\mathrm{X}_{1}, \mathrm{~mL} / \mathrm{g}\right)\end{array}$ & 43 & 50 & 60 & 70 & 77 \\
\hline $\begin{array}{l}\text { Ethanol } \\
\text { concentration } \\
\left(\mathrm{X}_{2}, \% \mathrm{v} / \mathrm{v}\right)\end{array}$ & 23 & 30 & 40 & 50 & 57 \\
\hline $\begin{array}{l}\text { Extraction time } \\
\left(\mathrm{X}_{3}, \mathrm{~min}\right)\end{array}$ & 35 & 50 & 70 & 90 & 105 \\
\hline
\end{tabular}

Table 3. The three - factor CCD matrix

\begin{tabular}{|c|c|c|c|}
\hline Run no. & $\mathbf{X}_{1}$ & $\mathbf{X}_{2}$ & $\mathbf{X}_{3}$ \\
\hline 1 & $1-$ & $1-$ & $1-$ \\
\hline 2 & 1 & $1-$ & $1-$ \\
\hline 3 & $1-$ & 1 & $1-$ \\
\hline 4 & 1 & 1 & $1-$ \\
\hline 5 & $1-$ & $1-$ & 1 \\
\hline 6 & 1 & $1-$ & 1 \\
\hline 7 & $1-$ & 1 & 1 \\
\hline 8 & 1 & 1 & 1 \\
\hline 9 & -1.682 & 0 & 0 \\
\hline 10 & 1.682 & 0 & 0 \\
\hline 11 & 0 & -1.682 & 0 \\
\hline 12 & 0 & 1.682 & 0 \\
\hline 13 & 0 & 0 & -1.682 \\
\hline 14 & 0 & 0 & 1.682 \\
\hline 15 & 0 & 0 & 0 \\
\hline 16 & 0 & 0 & 0 \\
\hline 17 & 0 & 0 & 0 \\
\hline 18 & 0 & 0 & 0 \\
\hline 19 & 0 & 0 & 0 \\
\hline 20 & 0 & 0 & 0 \\
\hline
\end{tabular}

\subsection{Optimization by RSM}

RSM is a statistical tool for modeling the relationship between decision variables and dependent variable, in the form of reduced second order model. In this research, the reduced second order model represented the relationship between extraction conditions and TPC yield. The reduced second model was then used as the objective function in the optimization problem. Microsoft Excel 
Solver was used to solve the nonlinear objective model for the maximum TPC yield.

The optimization formulation used in this work is as follow. In the formulation, all values of decision variables are in coded variables.

Optimization Formulation:

MAX: the reduced second order model

Decision variables: $x_{i} ; i=1,2,3$

Subject to: $-1.682 \leq \mathrm{x}_{\mathrm{i}} \leq 1.682$

\section{Results and Discussions}

The results of regression analysis show that main effects of ratio of solvent to material $\left(\mathrm{x}_{1}\right)$, ethanol concentration $\left(\mathrm{x}_{2}\right)$, and extraction time $\left(\mathrm{x}_{3}\right)$, and pure interaction of ethanol concentration have significant impact on the TPC extraction yield. Equation 1 represents the reduced second order model of this study, with the values of $\mathrm{R}^{2}$ is 0.8338 , and adjusted $\mathrm{R}^{2}$ is 0.7895 . The dependent variable $\mathrm{y}$ is the TPC extraction yield. The criteria to determine significant variables of this reduced model is $\mathrm{p}$-value $<0.05$.

$$
y=32.87-8.33 x_{1}+6.45 x_{2}-8.79 x_{3}+8.61 x_{2}^{2}
$$

This reduced second order (nonlinear) model was used as the objective function in the optimization problem. This nonlinear model was then optimized. Table 4 shows the optimal extraction conditions and corresponding TPC extraction yield. In Table 4, predicted TPC extraction yield is a predicted value from the reduced second order model. An actual TPC extraction yield was obtained from running experiments with optimal extraction conditions. The experiments were performed for three replications. The actual result shows higher TPC extraction yield than the predicted one. The percent error between the actual and predicted TPC extraction yield is around $13.7 \%$

Table 4. Optimal extraction conditions

\begin{tabular}{|l|c|}
\hline \multicolumn{1}{|c|}{ Variables } & Optimal value \\
\hline $\begin{array}{l}\mathrm{x}_{1}: \text { Ratio of solvent to material } \\
(\mathrm{mL} / \mathrm{g})\end{array}$ & 43 \\
\hline $\mathrm{x}_{2}:$ Ethanol concentration (\%) & 57 \\
\hline $\mathrm{x}_{3}:$ Extraction time (min) & 35 \\
\hline $\begin{array}{l}\text { Predicted TPC extraction yield } \\
\text { (mg GAE/g) }\end{array}$ & 96.49 \\
\hline $\begin{array}{l}\text { Actual TPC extraction yield } \\
\text { (mg GAE/g) }\end{array}$ & 111.77 \\
\hline
\end{tabular}

\section{Conclusions}

Response surface methodology is successfully applied to optimization of ultrasound assisted extraction of total phenolic compounds from leaves of Chromolaena odorata L. The reduced second order model represented the relationship between extraction conditions and TPC extraction was obtained. The obtained maximum TPC extraction is $111.77 \mathrm{mg} \mathrm{GAE} / \mathrm{g}$ with extraction conditions of Ratio of solvent to material at $43 \mathrm{~mL} / \mathrm{g}$, ethanol concentration at $57 \%$, extraction time at 35 minutes.

\section{Acknowledgements}

The research team would like to thank the RSPG and Dr.Santi Watthatana for providing Siam weed and recommendations.

\section{References}

Akinmoladun, A. F., E. Ibuken, and I. A. Dan-Ologe; "Phytochemical Constituents and Antioxidant Properties of Extracts from the Leaves of Chromolaena odorata," Sci. Res. Essays, 2(6), 191-194 (2007)

Alara O. R., N. H. Abdurahman, and S. K. A. Mudalip; "Optimizing Microwave-Assisted Extraction Conditions to Obtain Phenolic-Rich Extract from Chromolaena odorata Leaves," Chem. Eng. Technol., 42(9), 17331740 (2019)

Azmir, J., S. M. Zaidul, M. M. Rahman, K. M. Sharif, A. Mohamed, F. Sahena, M. H. A. Jahurul, K. Ghafoor, N. A. N. Norulaini, and K. M. Omar; "Techniques for Extraction of Bioactive Compounds from Plant Materials: A Review," J. Food Sci. Technol., 55(3), 977-984 (2013)

Chakraborty, A. K., S. Rambhade, and U. Patil; “Chromolaena odorata (L.) : An Overview, ” JPR, 4(3), 573-576 (2011)

Huang, W., A. Xue, H. Niu, Z. Jia, and J. Wang; "Optimised Ultrasonic-assisted Extraction of Flavonoids from Folium eucommiae and Evaluation of Antioxidant Activity in Multi-test Systems in vitro," Food Chem., 114(3), 1147-1154 (2009)

Liu, Y., X. Luo, Z. Lan, J. Tang, P. Zhao, and H. Kan; "Ultrasonic-assisted Extraction and Antioxidant Capacities of Flavonoids from Camellia fascicularisleaves," CYTA-J. Food, 16(1), 105-112 (2017)

Okpuzar, J., H. Ogbunugafor, G. K. Kareem, and M. N. Igwo-Ezikpe; "In vitro Investigation of Antioxidant Phenolics Compounds in Extract of Senne alata," Res. J. Phytochem., 3, 68-76 (2009)

Panche, A. N., A. D. Diwan and S. R. Chandra; "Flavonoids: An Overview," J. Nutri. Sci., 5, 1-15 (2016)

Pandey, A., T. Belwal, K. C. Sekar, I. D. Bhatt, and R. S. Rawal; "Optimization of Ultrasonic-assisted Extraction (UAE) of Phenolics and Antioxidant Compounds from Rhizomes of Rheum moorcroftianum using Response Surface Methodology (RSM)," Ind. Crops. Prod., 119, 218-225 (2018)

Sheng, Z., Y. Wang, P. Wan and Y. Li; "UltrasoundAssisted Extraction of Total Flavonoids from Leaves of Syringa Obalata Lingl," Lat. Am. Appl. Res., 44, 131-135 (2014)

Stalikas, C. D.; "Extraction, Separation, and Detection Methods for Phenolic Acids and Flavonoids," J. Sep. Sci. 30, 3268-3295 (2007)

Sulaiman, C. T. and I. Balachandran; "Total Phenolics and Total Flavonoids in Selected Indian Medicinal Plants," Indian J. Pharm. Sci., 74(3), 258-260 (2012) 